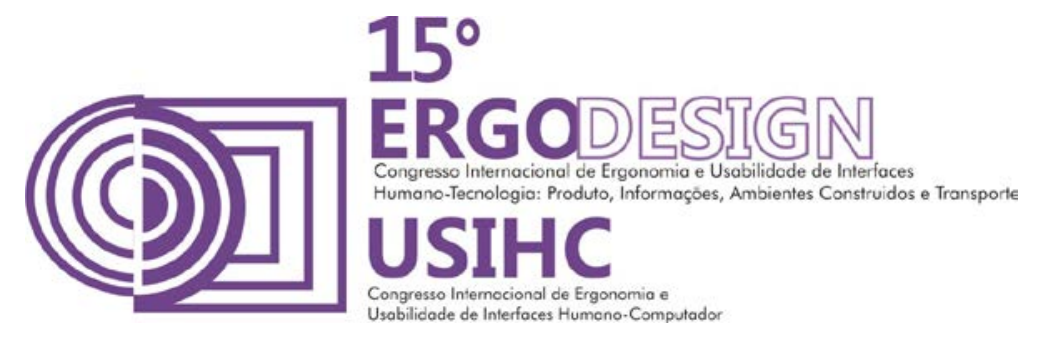

\title{
A ACESSIBILIDADE EM PROJETOS HABITACIONAIS DE INTERESSE SOCIAL: UMA EXPERIÊNCIA DE ENSINO NO CURSO TÉCNICO DE EDIFICAÇÕES DO IFBA - CAMPUS FEIRA DE SANTANA.
}

\section{ACCESSIBILITY IN SOCIAL HOUSING PROJECTS: A TEACHING EXPERIENCE IN TECHNICAL COURSE IN BUILDING FROM IFBA- FEIRA DE SANTANA CAMPUS}

\author{
FULGÊNCIO, Vinícius (1); \\ VILLAROUCO, Vilma (2);
}

(1) Docente do Instituto Federal da Bahia, Mestrando em Desenvolvimento Urbano

e-mail:vaf.vinicius@gmail.com

(2) Docente da Universidade Federal de Pernambuco, Doutora em Engenharia de Produção

e-mail:villarouco@hotmail.com

\begin{abstract}
RESUMO
Projetos habitacionais de interesse social costumam apresentar áreas reduzidas devido aos custos. Apesar desses condicionantes é preciso e possível desenvolver esses tipos de ambiente adaptados ao usuário. Nesse contexto, foi realizada, com os alunos do Curso Técnico Médio em Edificações do IFBA Campus Feira de Santana, uma atividade de produção habitacional de baixo custo, mas que considerasse aspectos como ventilação, insolação, instalações, dimensionamento, atividades e acessibilidade. Assim, o presente trabalho intenta, a partir das analises, verificar os níveis de acessibilidade das propostas no intuito de averiguar a aprendizagem desse conteúdo específico.
\end{abstract}

Palavras-chave: Acessibilidade; Habitação Social; Projeto Arquitetônico; Ensino de Projeto

\section{ABSTRACT}

Housing schemes which have social interest usually introduce downscaled areas because of the costs. Despite of these constraints it is necessary and also possible to develop these kinds of spaces adapted to the users. In this context, it was held with the students of Technical Course in Building from IFBA Campus Feira de Santana, a housing production activity of low cost but considering aspects such as ventilation, heat, facilities, design, activities and affordability. Therefore this study aims, from the analysis, check the accessibility levels of the proposals in order to investigate the learning of this specific content.

Keywords: Accessibility; Social housing; Architectural Design; Project Education 


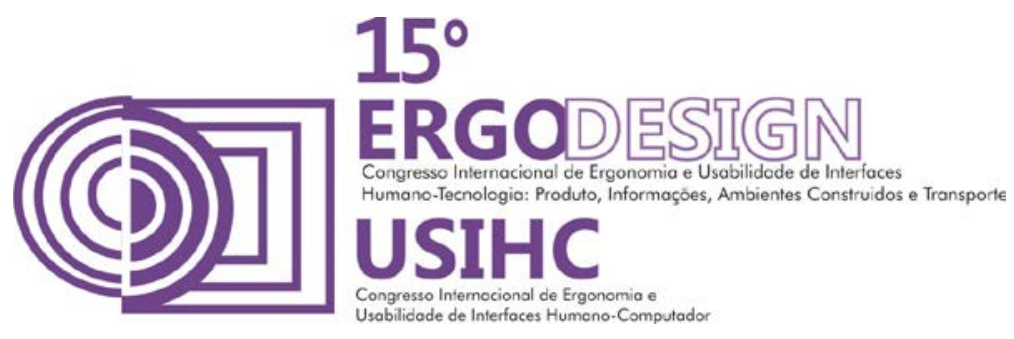

\section{INTRODUÇÃO}

A dificuldade do acesso à moradia urbana está, ao longo da história, relacionada ao processo de industrialização que conquista abruptamente os grandes aglomerados urbanos (DE SOUSA et al, 2011). No ano de 2000 o déficit habitacional em áreas urbanas era de 5,5 milhões de moradias, sendo mais graves para as famílias de 0 a 3 salários mínimos (LEITE, 2006). Já em 2007 esse número vai para 6 milhões, sendo 2 milhões na Região Nordeste ( DOS SANTOS, 2011). Trata-se de uma questão latente na sociedade e que se arrasta por décadas.

Oliveira e Mont'Alvão (2014), Ching (1998), Kowaltowski et al (2011), Bernardi et al ( 2011) e Leite (2006), abordam a necessidade de uma produção arquitetônica que satisfaça as necessidades do homem, bem como das atividades exercidas por ele nos ambientes. No campo do ensino de projeto, aponta Del Rio (1998) que para além das divergências entre os defensores da função e os partidários da forma arquitetônica, faz-se necessário promover um novo modelo de ensino que centre o usuário nas decisões projetuais.

Nesse sentido, foi realizado, no IFBA-Campus Feira de Santana, um minicurso de projeto habitacional voltado para o interesse social que ocorreu na Semana Nacional de Ciência e Tecnologia de 2014. O minicurso tinha como público os estudantes do Curso Técnico de nível médio em Edificações, uma vez que esses profissionais estão habilitados a se responsabilizarem pelo projeto e execução de obras conforme as restrições das resoluções $n^{\circ}$ 262/79 e $n^{\circ}$ 278/83, referentes ao Decreto Federal $n^{\circ}$ 90.922/85. Além de capacitar para a atuação direta no mercado de trabalho, essas atividades promovem competências básicas para a continuidade dos estudos em cursos de nível superior na área da construção civil, como Arquitetura e Engenharia.

No sentido de avaliar as respostas obtidas em termos da produção final desse minicurso, o presente trabalho visa analisar os níveis de acessibilidade em cada proposta de unidade habitacional, tendo como foco o cadeirante, uma vez que a estrutura do curso, ao tratar da acessibilidade, enfoque nesse usuário.

\section{FUNDAMENTAÇÃO TEÓRICA.}

\subsection{Arquitetura e Projeto.}

Historicamente o entendimento da arquitetura aparece com significados maleáveis. Diversas interpretações foram feitas sobre o mesmo artefato arquitetônico ao longo dos tempos (DE CARVALHO, 2004). As primeiras definições alusivas à arquitetura remetem à obra "De Architectura Libri Decem" do arquiteto romano Marcus Vitruvius Pollio. Nesse texto são percebidos como fundamentais à arquitetura três aspectos: a solidez, a utilidade e a beleza.

Para Hollier (1993) apud Jacques (2003) o que diferencia um objeto arquitetônico de uma construção qualquer seria o não construído, ou seja, o vazio, fugindo das referências relativas ao espaço utilitário. Nesse sentido, a arte da arquitetura, como elemento da cultura humana, só se concretiza quando construída, uma vez que seu canal semiótico é o espaço (COUTINHO, 1977).

Assim, o caminhar é a maneira mais apropriada para entender um artefato arquitetônico. Os percursos entre os espaços internos e externos do edifício permitem estabelecer relações entre 


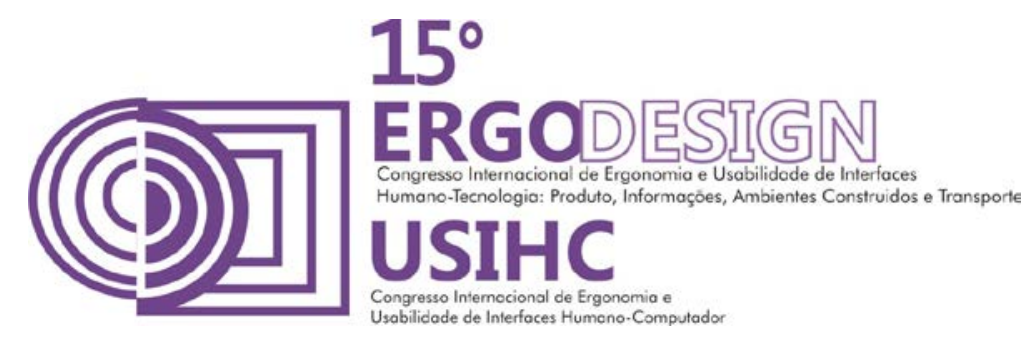

eles (ZEVI, 1996). Daí está o grande diferencial da atividade teórica da arquitetura, pois é essencial a dimensão prática da experimentação dos espaços vividos, indo para muito além da contemplação (BRANDÃO, 2003).

É inerente à arquitetura o cumprimento de um programa construtivo para abrigar atividades humanas. No entanto, a disposição dos espaços determina a maneira como a arquitetura pode promover inciativas, obter respostas e transmitir significado (CHING, 1998). Essas reações provocadas pelo espaço são definidas por Norberg-Schulz (1973) como espaço existencial, em que cada ação humana tem um aspecto espacial definido por uma estrutura física.

Nesse sentido, o projeto de arquitetura precisa cumprir as expectativas do cliente, compilando soluções que considerem os aspectos estéticos, utilitários, estruturais e de custo. Trata-se, em um determinado nível, de um exercício dialético e constante de antecipação, imaginação e conjecturas (OLIVEIRA; MONT'ALVÃO, 2014).

As referências ao processo do projeto arquitetônico foram construídas a partir de uma conotação de um processo linear (SILVA, 1991), ou seja, partindo de um ponto inicial (problema a ser resolvido ou demandas a serem sanadas) e chegando a um destino final que seria a solução acabada do problema ou demanda. Oliveira e Mont'Alvão (2014) salientam que essa ideia de acontecimentos sequenciados configuram-se como obstáculos nesse processo, haja vista que, em muitos casos, ocorrem imprevisibilidades das ações projetuais.

Dessa forma, Lawson (2011) apud Oliveira e Mont'Alvão (2014) elucida a construção do processo projetual como um evento cíclico , flexível e articulado composto por três elementos: análise, síntese e avaliação. O primeiro identifica os principais fatores do problema do projeto, bem como determina os principais objetivos, metas, restrições e impactos. O segundo caracteriza-se por ser a fase onde a criatividade se insere no processo conceptual e na construção de soluções. O terceiro e não último, pois trata-se de um processo cíclico, refere-se a verificação da qualidade da proposta, buscando os problemas do projeto antes de sua execução, venda ou uso.

Estudos que procurem melhorar o processo do projeto são importantes para a melhoria dos ambientes. Potencializar o processo projetual é desenvolver uma arquitetura de alto desempenho, menores impactos, apresentando amplas vantagens e, principalmente, adaptados às necessidades dos usuários, bem como do ambiente de entorno (KOWALTOWSKI, 2011).

Quanto às questões concernentes ao ensino do projeto de arquitetura, Del Rio (1998) aborda os inúmeros desafios, bem como tece algumas diretrizes em sua obra Arquitetura: Pesquisa \& Projeto. O autor aponta os aspectos relacionais da arquitetura como o desenho, o projeto, 0 método, a função, os conflitos teóricos e práticos (acadêmicos e de mercado). Elucida-se sobre a dicotomia entre os defensores do repertório da forma e do tipo e os patronos da funcionalidade. Quando na verdade o processo do projeto é uma construção dialética entre esses e outros elementos. Dentre diversas contribuições, o autor afirma a importância de um novo caminho no ensino do projeto que deve considerar três pontos: o usuário, o contexto espacial e as teorias das ciências sociais aplicadas. 


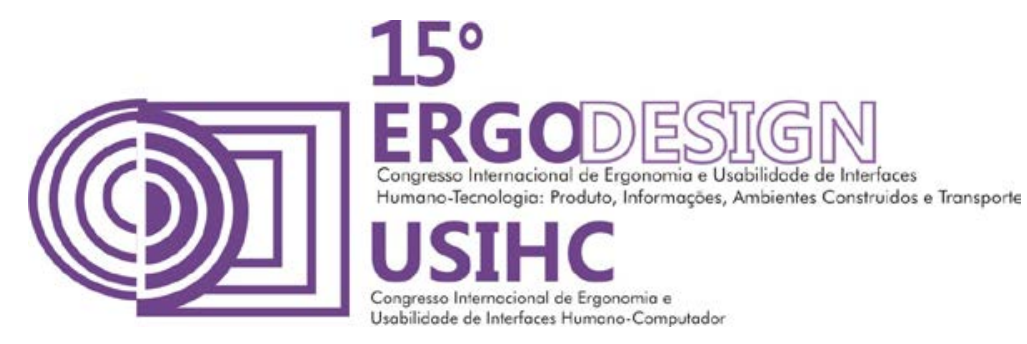

\subsection{Acessibilidade.}

Antes ocultos, indivíduos com necessidades específicas de auxílio para locomoção, comunicação ou outras atividades aparecem como uma demanda crescente. Com os avanços da medicina e o aumento da estimativa de vida, essas pessoas começam a ocupar diversos espaços na sociedade e exigindo seus direitos a trabalho, moradia, lazer e a vivencia em comunidade (BERNARDI et al, 2011). Assim, para que tenhamos espaços que propiciem essas relações sociais é preciso que eles sejam funcionais (LEITE, 2006).

Ao tratamos da acessibilidade de um ambiente, é importante a identificação e compreensão de elementos que impedem ou restringem o usuário de perceber, compreender, circular ou se apropriar dos espaços e atividades nos quais ele está inserido. Além disso, é preciso estar atento a obstáculos de natureza não física, como barreiras socioculturais e de informação (BINS ELY, DISCHINGER e MATTOS, 2002).

Em termos mais diretos e amplos, a acessibilidade é um atributo essencial ao espaço físico que tem como cerne o ser humano (SÃO PAULO, nd.). Para Voord \& Wegen (2005), a acessibilidade é um dos elementos para a promoção de espaços seguros e que produzem bem estar aos usuários.

Um projeto acessível coloca-se, então, como àquele adaptado a determinadas necessidades de usuários específicos, diferenciando-se do desenho universal, cuja conotação se remota para um projeto para todos, sem descriminação e apresenta-se desde o início conceptivo do projeto (DORNELES et al, 2014). Dessa maneira, é possível aferir que enquanto a acessibilidade resolve questões pontuais, o desenho universal se volta para questões mais amplas do projeto.

Em termos amplos conceituais, o que torna um projeto arquitetônico acessível é a sua capacidade de contemplar a legibilidade do espaço, legibilidade gráfica e preocupado com a antecipação (BERNARDI et al, 2011).

Ainda segundo Bernardi et al (2011), a acessibilidade apresenta-se, cada vez mais, como um grande desafio para a sociedade, governo e arquitetos (ampliemos para todos os profissionais envolvidos na construção civil). Esses últimos atuam diretamente na materialização dos ambientes e devem considerar a acessibilidade desde a fase conceptual do projeto.

No Brasil, através da Lei No. 10.098 de 2000, foram estabelecidas normas gerais e critérios básicos para promover a acessibilidade para pessoas portadoras de deficiência ou com mobilidade reduzida (ABNT, 2004).

Dentre diversas questões abordadas, a referida norma indica parâmetros antropométricos, considerando indivíduos que se desloquem com bengalas, andadores, muletas e cadeiras de rodas. Há também as recomendações de áreas mínimas para as rotações de cadeirantes em $90^{\circ}, 180^{\circ}$ e $360^{\circ}$. Apresenta também as dimensões mínimas para banheiros nas mais diversas configurações (com uma, duas ou três peças), considerando as áreas de giro e de transferência.

Para o caso de um projeto habitacional acessível, faz-se necessário considerar três principais diretrizes: acesso ao interior livre de escadas, degraus e, caso existam, que haja a presença de rampas ou elementos mecânicos; as portas devem apresentar larguras que permitam a 


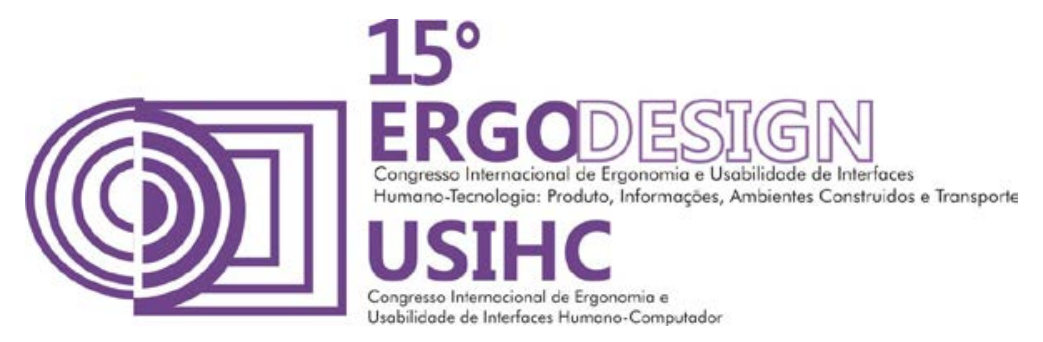

passagem de uma cadeira de rodas; ao menos um dos sanitários deve permitir o uso, com autonomia, por um cadeirante (SÃO PAULO, nd.).

\section{A EXPERIÊNCIA NO CURSO TÉCNICO EM EDIFICAÇÕES DO IFBA-CAMPUS FEIRA DE SANTANA.}

\subsection{A Justificativa da Proposta.}

O Instituto Federal da Bahia (IFBA), assim como diversos outros Institutos Federais, oferece o curso Técnico de nível médio em Edificações: modalidade educação profissional integrada ao ensino médio. Trata-se de um curso único, realizado de forma integrada e interdependente, de modo que as conclusões do ensino médio e do ensino profissional estão interligadas. Os estudantes que concluam todas as etapas, formadas por quatro séries (um ano cada) e estágio, receberão o Diploma de Técnico em Edificações (IFBA, 2011). O Campus Feira de Santana, em especial, ainda não formou nenhuma turma dessa modalidade haja vista que o curso teve início em 2012.

As Resoluções $n^{\circ} 262 / 79$ e $n^{\circ} 278 / 83$, ambas dispostas referentes ao Decreto Federal $n^{\circ}$ 90.922/85, trazem as atribuições profissionais do Técnico em Edificações. Com relação às atividades referentes a projeto e acompanhamento de obra o artigo $4^{\circ}$,em seu $1^{\circ}$ parágrafo, dispõe que: "Os técnicos de $2^{\circ}$ grau das áreas de Arquitetura e de Engenharia Civil, na modalidade Edificações, poderão projetar e dirigir edificações de até $80 \mathrm{~m}^{2}$ de área construída, que não constituam conjuntos residenciais, bem como realizar reformas, desde que não impliquem em estruturas de concreto armado ou metálica, e exercer a atividade de desenhista de sua especialidade." (BRASIL, 1985).

Assim, é importante que esse profissional saia do curso com competências mínimas para a execução dessas funções, principalmente no contexto socioeconômico de Feira de Santa e sua região de entorno imediato onde, muitas vezes, esses profissionais atuam fortemente pela falta de profissionais da área como Arquitetos e Engenheiros.

Inúmeras questões poderiam ser aqui levantadas, mas infelizmente seria um trabalho inacabado. O fato concreto é que a lei permite a realização de uma função que tem impacto direto na vida da população.

Diante disso, foi realizado, no IFBA- Campus Feira de Santana, um minicurso sobre Projeto de Habitação de Interesse Social. Esse minicurso foi resultado de um projeto maior: a Semana Nacional de Ciência e Tecnologia de 2014, cuja temática foi a Ciência e Tecnologia para 0 Desenvolvimento Social.

Trata-se de uma demanda latente haja vista que mais de 1 milhão de pessoas vivam no país de maneira informal. Há uma prospecção de que em um quarto de século essa população aumentará aproximadamente em 40\%. Dessa maneira, é preciso que planejadores, técnicos, governantes e empresários estejam preparados para atender essa problemática (RAPOSO, 2012).

Sabemos que ao tratarmos de habitações de interesse social, estamos falando da produção em larga escala. Por tanto, de acordo com o Decreto Federal $n^{\circ}$ 90.922/85 o Técnico em Edificações não poderia exercer funções de projetista. No entanto, esse profissional pode está inserido no processo dessa produção e, dessa forma, ferramentas que melhor o capacitem são 


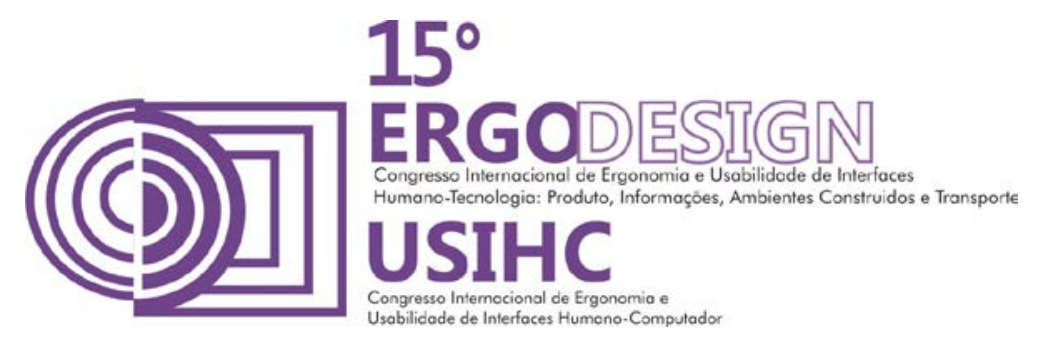

importantes para a inserção desse profissional no mercado de trabalho. Os conceitos aplicados também serviram de base para a aplicação em habitações que, mesmo construídas por iniciativa privada e individual, possuem um capital baixo, considerando a realidade local.

Ademais, em termos acadêmicos, o Plano de Curso apresenta, nas ementas das disciplinas de Desenho Arquitetônico I e II, os conteúdos relativos a dimensionamento, noções de ventilação e iluminação, cálculo de rampas, escadas e acessibilidade.

A partir das breves considerações anteriores, é possível compreender a necessidade de se trabalhar esses conteúdos em Curso Técnicos de Edificações, bem como o porquê desse trabalho. Salienta-se aqui que não se trata de colocar pontos finais, mas de propor o debate e estudos que considerem esse contexto.

\subsection{O minicurso}

O objetivo do minicurso era desenvolver um projeto de habitação voltado para o Interesse Social, considerando condicionantes locais e demandas de marcado, bem como o conforto e as apropriações espaciais do ambiente construído.

Como havia alunos de 3 séries diferentes, nem todos sabiam utilizar softwares computacionais como o AutoCAD. Assim, todo o processo projetivo foi desenvolvido por meio de desenhos feitos à mão, desde os conceptivos até a planta baixa final. Devido ao pouco tempo disponível para o minicurso, o produto final de cada projeto foi apenas a planta baixa e uma perspectiva isométrica (única ferramenta de representação tridimensional que os estudantes possuíam).

O minicurso foi desenvolvido em 2 etapas: uma teórica e outra prática. No momento teórico foram trabalhados os seguintes temas: o cenário habitacional brasileiro, as tipologias de habitação de baixa renda, o processo projetivo, noções de acessibilidade, dimensionamento e, por fim, foram apresentados estudos de caso. A etapa prática foi constituída pela elaboração do projeto, a partir do seguinte programa básico: sala, cozinha, área de serviço, bwc, quarto de casal e quarto de solteiro que não deveriam ultrapassar $60 \mathrm{~m}^{2}$, considerando que $57 \mathrm{~m}^{2}$ seria suficiente conforme a Tabela 01 a seguir.

\begin{tabular}{|c|c|c|c|}
\hline Tipologia & $\begin{array}{l}\text { Area sem Desenho } \\
\text { Universal (em m2) }\end{array}$ & $\begin{array}{l}\text { Área com Desenho } \\
\text { Universal (em m2) }\end{array}$ & $\begin{array}{l}\text { Incremento } \\
\text { de área (em \%) }\end{array}$ \\
\hline $\begin{array}{l}\text { Casa térrea } \\
2 \text { dormitórios }\end{array}$ & 50,00 & 57,00 & 14,0 \\
\hline $\begin{array}{l}\text { Casa térrea } \\
3 \text { dormitórios }\end{array}$ & 60,00 & 66,00 & 10,0 \\
\hline $\begin{array}{l}\text { Apartamento } \\
2 \text { dormitórios }\end{array}$ & 52,50 & 58,00 & 10,5 \\
\hline $\begin{array}{l}\text { Apartamento } \\
3 \text { dormitórios }\end{array}$ & 65,00 & 68,00 & 4,6 \\
\hline
\end{tabular}

Tabela 01 - Relação entre metragem quadrada e tipologia habitacional. Fonte: (SÃ̃o PAULO, nd.).

Os 8 alunos inscritos se agruparam em 4 duplas, uma dupla da primeira série, duas duplas da segunda série e uma dupla da terceira série. Por tanto, tivemos como produtos finais quatro plantas baixas e apenas três perspectivas, já que a dupla formada por alunos da $1^{a}$ série ainda aprendiam o processo de construção gráfica da perspectiva. 


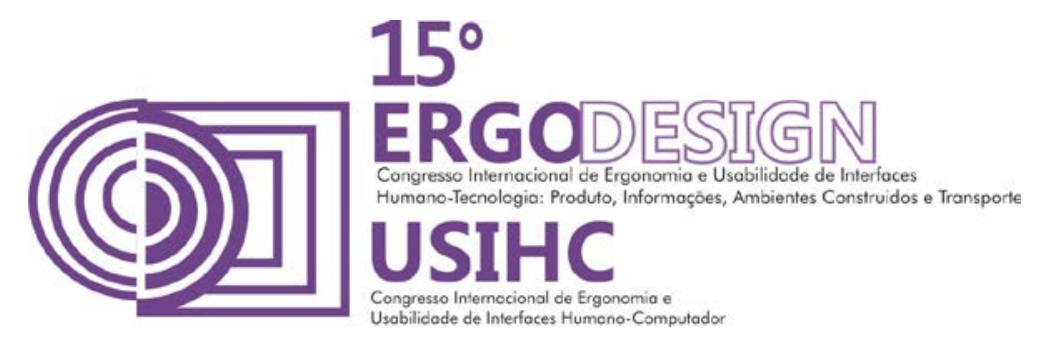

De antemão é preciso constar que o tempo formal desse minicurso foi de 8h, mas na prática foi de 12h. Mesmo assim, o tempo foi insuficiente para as questões levantadas, bem como para o nível de complexidade do tema. Além disso, tratam-se de alunos com diferentes níveis, uma vez que eram de diferentes séries, conforme já mencionado.

No entanto, a experiência tornou-se válida não só por abordar uma temática que é uma necessidade prática da realidade, como também pela inserção desses alunos no processo do projeto, considerando as questões já anteriormente levantadas.

\section{ANÁLISE DO NÍVEL DE ACESSIBILIDADE DOS PROJETOS.}

\subsection{Procedimentos}

A análise se coloca como um elemento de antecipação abordados por Oliveira e Mont'Alvão (2014) e Bernardi et al (2011), retroalimentando o processo projetual e seu ciclo de análise, síntese e avaliação na perspectiva desenvolvida por Lawson (2011) apud Oliveira e Mont'Alvão (2014).

Nessa análise será tratada apenas a acessibilidade relativa ao cadeirante. Sabemos que a acessibilidade compreende outros usuários, mas é preciso recortar o estudo por duas questões: procedimentais (para uma análise mais eficiente) e acadêmicas (uma vez que a acessibilidade abordada no Curso Técnico em Edificações enfoca nesse público).

Assim, o estudo analisará apenas os aspectos referentes aos espaços horizontais, haja vista que só foram desenvolvidas plantas baixas no minicurso. Essas condições vão considerar os parâmetros fornecidos pela NBR 9050 bem como as diretrizes apontadas no manual de desenho universal para habitações de interesse social (SÂO PAULO, nd.), citadas no item 2.1 desse trabalho. Para uma melhor desenvoltura da análise, foram elaboradas algumas ferramentas para melhor compreensão das condições de acessibilidade dos projetos propostos em nível de planta baixa. Foram criados símbolos (Figura 1) para identificar esse afinamento, ou não, com as diretrizes consideradas, onde o vermelho significa o impedimento, o amarelo indica uso com restrições e o verde o uso satisfatório.

\section{(E) com impedimento $G$ com restriçōes \& satisfatório}

Figura 1 - Símbolos de identificação do nível de acessibilidade. Fonte: Os autores

\subsection{Análise dos projetos.}

Antes de tratarmos os casos em suas especificidades, apresentaremos na Tabela 02 os índices de cumprimentos dos itens referentes aos seguintes pontos: acessos ao interior livres de escadas, degraus e, caso existam, que haja a presença de rampas ou elementos mecânicos (item 1); portas com larguras que permitam a passagem de uma cadeira de rodas, consideramos também as passagens como corredores (item 2); ao menos um dos sanitários que permita o uso por um cadeirante, com autonomia (item 3). A escala de pontuação varia de 0 a 1 , sendo 0 o não atendimento e 10 atendimento completo. É importante ressaltar que 


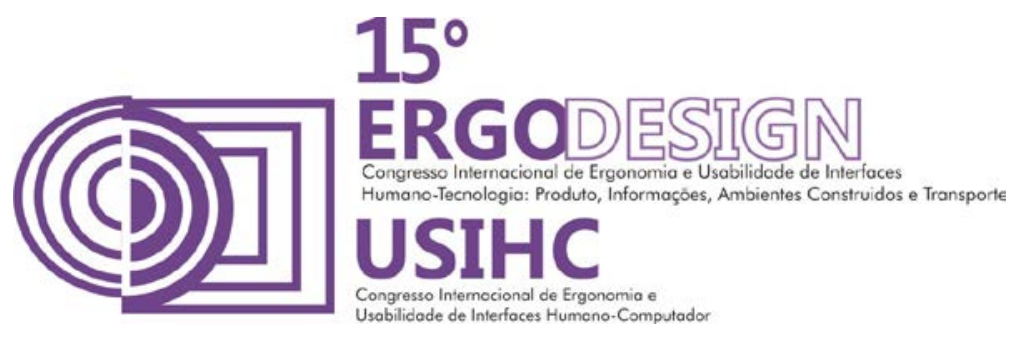

nesse cálculo, para o item 2, ponderou-se a relação de pontos com o número de portas e passagens, uma vez que as plantas apresentam configurações diferentes.

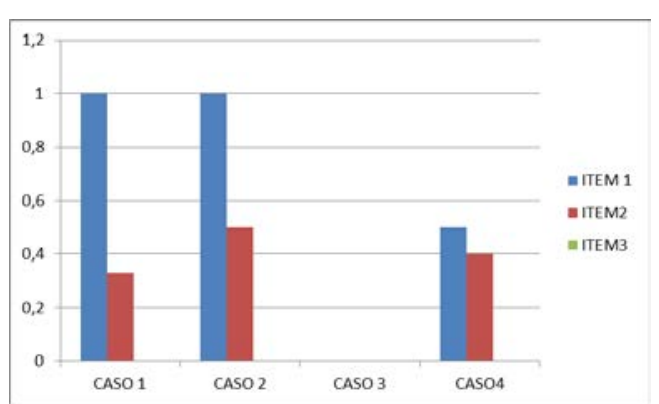

Tabela 02 - Índice de cumprimento dos Itens 1,2 e 3.

Fonte: Os autores

De antemão já é possível observar que nenhum dos projetos atenderam ao item 3, ainda que alguns banheiros possuíam portas que permitissem a entrada da cadeira de roda, nenhum atendeu as necessidades das rotações, áreas para transferência, nem indicaram a presença de barras de apoio.

Quanto ao item 1, os Casos 1 e 2 atenderam em 100\%, pois tratavam-se de casas térreas. O Caso 4 atendeu em 50\%, uma vez que a casa estava dividida em 2 pavimentos e não havia nenhum elemento mecânico que fizesse o deslocamento do cadeirante para o pavimento superior, sendo essa solução pouco provável na prática da produção habitacional de interesse social. Por fim, o Caso 3 apresentou a situação mais grave, pois a habitação foi pensada em três pavimentos cujo o único elemento de interligação era a circulação vertical por uma escada e, o térreo estava destinado à garagem. Quanto a este último aspecto, é importante destacar que, apesar do contexto socioeconômico do público alvo, os projetos de referência na habitação de interesse social estão incluindo esse elemento, uma vez que, nos projetos em que há participação dos usuários, o lugar para o carro apresenta-se como uma necessidade. Tendo isso em vista, os alunos deram espaço a esse item nos seus projetos, exceto pelo Caso 1.

Por último, abordaremos o item 2, pois foi aquele que apresentou a maior diversidades entre os casos. No Caso 1 apenas a porta de entrada permite o acesso pleno, bem como o vão entre a cozinha e a sala, os demais cômodos apresentaram portas de $60 \mathrm{~cm}$, impossibilitando o acesso pelo cadeirante, pontuando 0,33 . O Caso 2 foi o que teve a melhor pontuação $(0,5)$, vale salientar que todas as portas permitiam a passagem, mas com restrições, isso porque um vão livre de $80 \mathrm{~cm}$ indica que, na prática, o cadeirante usará a grade da porta ou as paredes para conseguir o impulso necessário para entrar no ambiente. Nesse caso, observa-se que o único impedimento de passagem é da cozinha para a área de serviço. O caso 3 apresentou-se, mais uma vez, como um caso crítico. Mesmo considerando que o cadeirante tenha acesso aos pavimentos seguintes, com auxílio - fugindo da noção de autonomia, nenhuma das portas e passagens permitia o livre acesso. $O$ caso 4 apresentou a segunda melhor pontuação $(0,4)$, no entanto o acesso ao pavimento superior, com autonomia, torna-se impossibilitado devido à escada.

A primeira proposta (Figura 02) atendeu ao programa de necessidades e respeitou a área máxima de $60 \mathrm{~m}^{2}$, tendo uma área total de $40,54 \mathrm{~m}^{2}$. A partir das considerações da Tabela 01, sabe-se que com essa metragem não seria possível alcançar uma unidade habitacional 


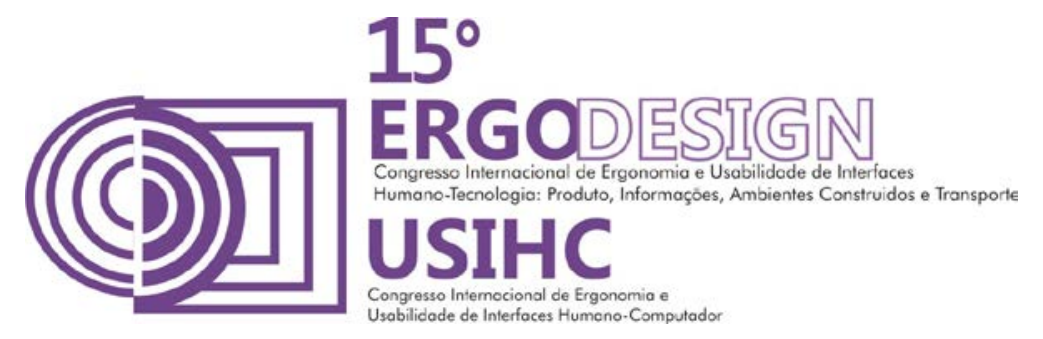

acessível (uma vez que a acessibilidade é parte do desenho universal). Além da impossibilidade de acesso aos quartos e banheiro, há poucas possibilidades de rotações de $90^{\circ}$, considerando que a combinação dessas e com a rotação de $180^{\circ} \mathrm{em}$ pontos estratégicos proporcionaria um melhor uso por um cadeirante. A habitação em questão possibilita apenas um uso restrito da sala e parte da cozinha.

A segunda proposta possui uma área total de $41,4 \mathrm{~m}^{2}$ e, apesar de estar distante dos $57 \mathrm{~m}^{2}$ indicados pela Tabela 01, foi a proposta, dentre as quatro, que melhor respondeu as necessidades de um usuário cadeirante, embora esteja um tanto insatisfatória. Além das questões referentes às portas, já tratadas no tópico anterior, é possível observar que apesar de existir acesso ao banheiro não há barras de apoio e nem área para transferência e giro. A área de serviço é inacessível, bem como a área do balcão para cocção e fogão, ficando o acesso restrito apenas à geladeira e pia. No centro geométrico da casa, um ponto estratégico para um giro de $180^{\circ}$, o layout impossibilita a manobra. O acesso aos quartos é possível com restrições, ou seja, com possíveis riscos ao usuário, no entanto o cadeirante não tem acesso ao guardaroupa, sendo desconfortável até mesmo para um não cadeirante, pois a distância entre a cama e o guarda-roupa é de $45 \mathrm{~cm}$.

Apesar de possuir $60 \mathrm{~m}^{2}$ de área construída, o Caso 3(Figura 05) foi o que teve o pior desempenho quanto a promoção de acessibilidade por duas principais razões: a tipologia vertical e o dimensionamento que sequer contempla os mobiliários mínimos para o uso dos ambientes.

O Caso 4 (Figura 06), assim como o Caso 3, teve baixo desempenho pela sua tipologia vertical, por outro lado, exceto pelo banheiro e pela cozinha, apresenta dimensões satisfatórias para as combinações de giros, tanto que foi a que apresentou a maior área $\left(90 \mathrm{~m}^{2}\right)$, desrespeitando o limite proposto de $60 \mathrm{~m}^{2}$.

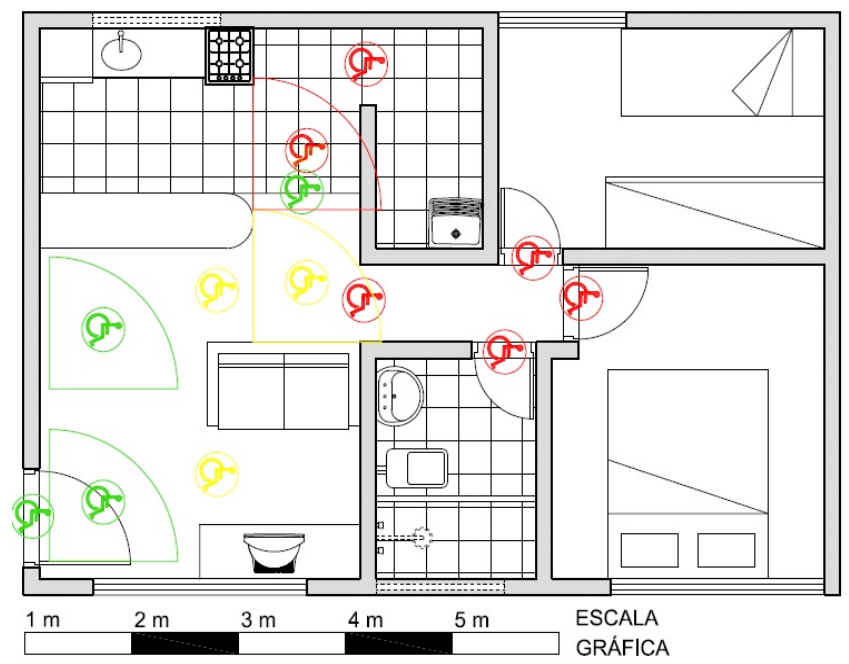

Figura 02 - Planta Baixa do Caso 1. Fonte: Os autores 

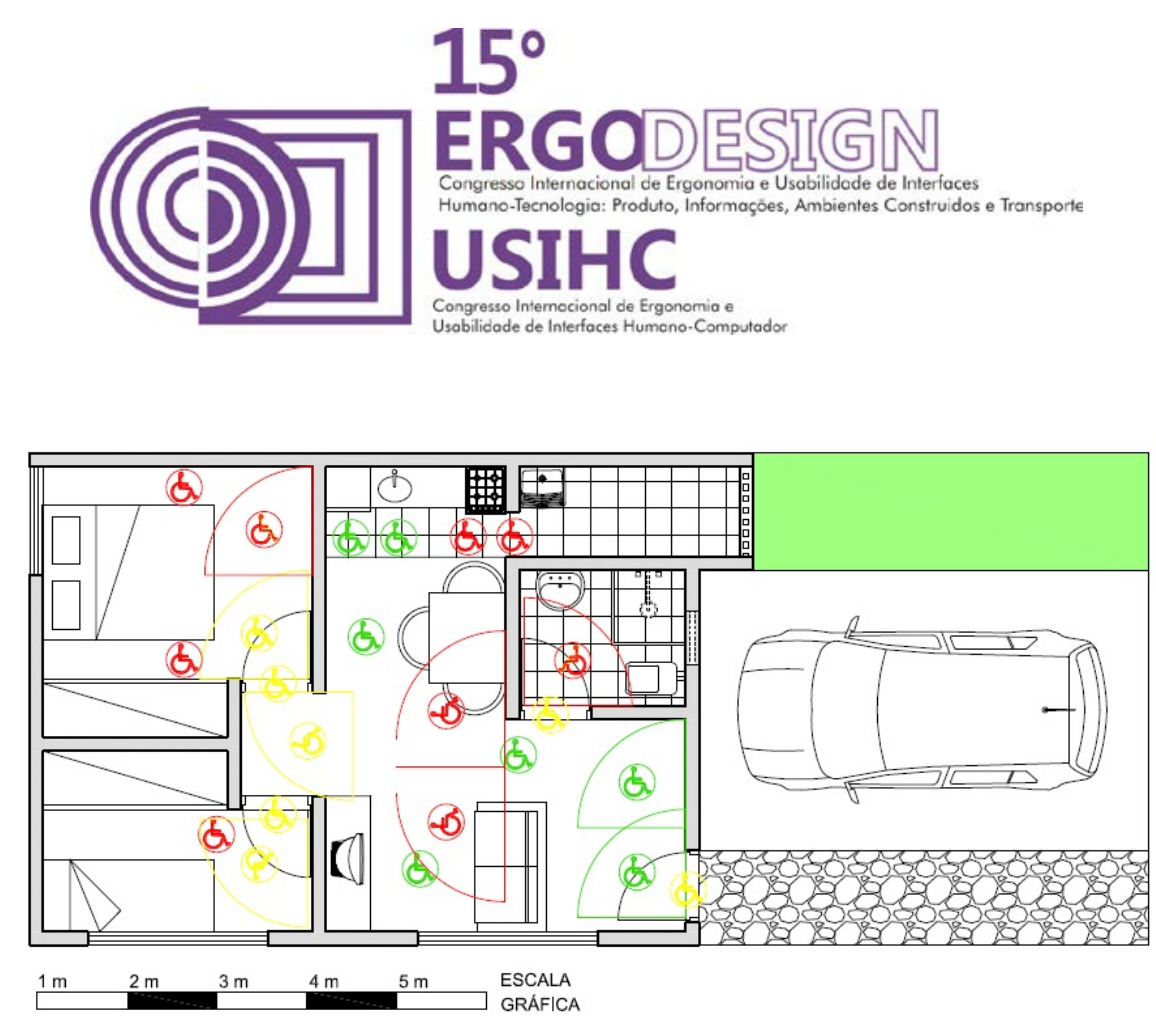

Figura 03 - Planta Baixa do Caso 2.

Fonte: Os autores.
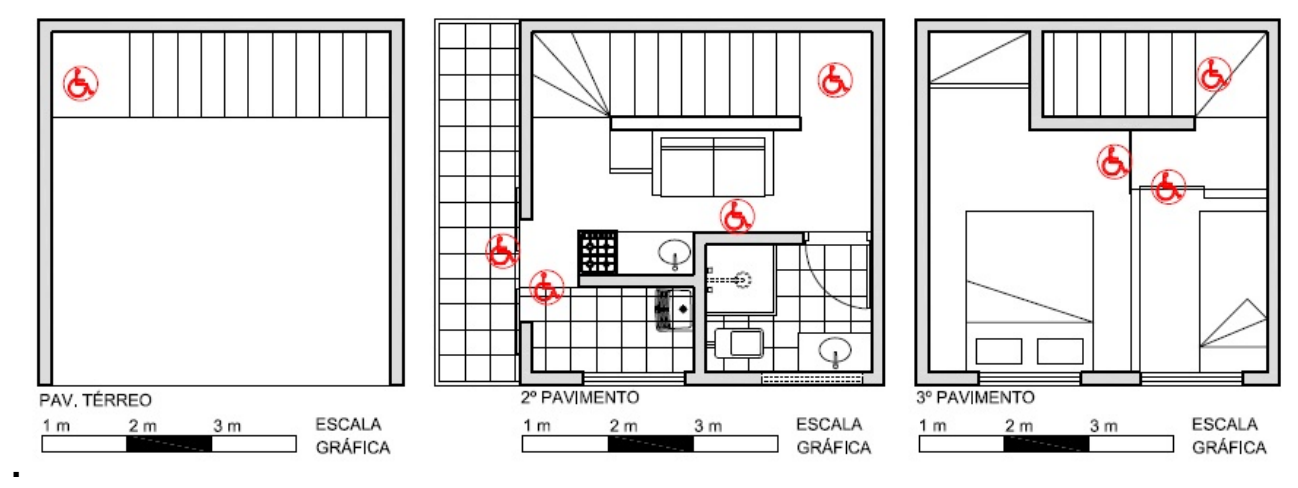

Figura 04 - Planta Baixa Caso 3.

Fonte: Os autores
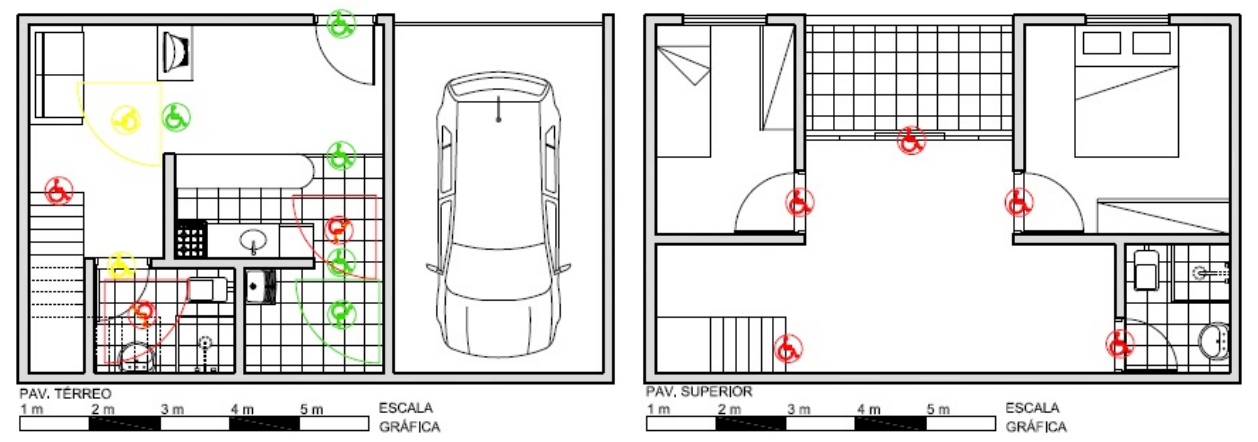

Figura 05 - Planta Baixa Caso 4.

Fonte: Os autores. 


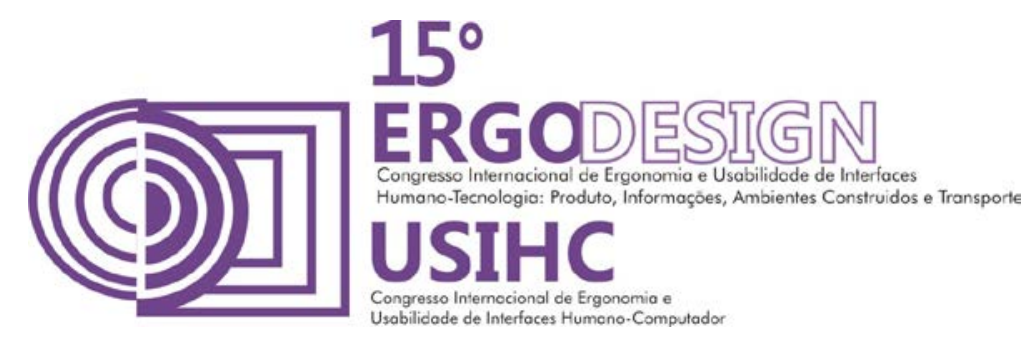

\section{CONSIDERAÇÕES FINAIS}

A partir das considerações teóricas e das análises desenvolvidas é possível aferir que a tipologia vertical de uma unidade habitacional configura-se como o primeiro elemento que contribui para o baixo nível de desempenho na promoção da acessibilidade.

Concluímos também que a metragem quadrada não é definidora para um uso pleno do espaço por um cadeirante, pois a disposição espacial e a tipologia interferem fortemente nesse aspecto, potencializando ou desabilitando o nível de qualidade do projeto.

É preciso repensar o vão livre de $80 \mathrm{~cm}$ para as portas, pois o cadeirante precisa apoiar-se em elementos verticais como a grade da porta ou a parede, podendo correr algum risco no uso do ambiente.

Observou-se também que o layout pode interferir nas possibilidades de combinação de giro, lembrando que o usuário tende, muitas vezes, alocar o mobiliário de maneira diferente de como o projetista planejou. Nesse sentido, Leite (2006) aponta a importância em orientar os usuários sobre o melhor aproveitamento espacial dos mobiliários e equipamentos, considerando as necessidades específicas de cada realidade.

A capacidade de representação gráfica também interferiu no processo do projeto. Nesse sentido, De Carvalho (2004) afirma a importância do desenho no processo projetual, sendo uma ferramenta importante no processo mental e reflexivo na busca das soluções de projeto.

Coloca-se então a necessidade de uma reestruturação didática, bem como uma abordagem contínua da acessibilidade como conteúdo das disciplinas de Desenho Arquitetônico I e II, previsto no Plano de Curso da Instituição em questão. Lembrando, de maneira exaustiva, que essa é uma necessidade prática uma vez que esses profissionais estão habilitados a desenvolverem e executarem projetos.

\section{REFERÊNCIAS BIBLIOGRÁFICAS}

ASSOCIAÇÃO BRASILEIRA DE NORMAS TÉCNICAS. NBR 9.050: Acessibilidade de pessoas portadoras de deficiências a edificações, espaço, mobiliário e equipamentos urbanos. Rio de Janeiro, 2004.

BERNARDI, Núbia et al. O desenho universal no processo de projeto. In: Doris C.C.K.Kowaltowski, Daniel de Carvalho Moreira, João R.D.Petreche, Mário M. Fabricio (Orgs.). O processo do projeto em arquitetura. São Paulo: Oficina de textos, 2011.

BINS ELY, V. H. M., DISCHINGER, M., MATTOS, M. L. Sistemas de Informação Ambiental Elementos Indispensáveis para Acessibilidade e Orientabilidade. Anais do ABERGO $2002-\mathrm{VI}$ Congresso Latino- Americano de Ergonomia e XII Congresso Brasileiro de Ergonomia. Recife, 2002.

BRANDÃO, Carlos. Linguagem e arquitetura: o problema do conceito. Minas Gerais, 2003.

BRASIL. Presidência da República/Casa Civill Subchefia para Assuntos Jurídicos. Decreto $n^{\circ}$ 90.922, de 6 de fevereiro de 1985. Disponível em http://www.planalto.gov.br/ccivil_03/decreto/antigos/d90922.htm, acessado em: 12/12/2014.

CHING, Francis D. K.. Arquitetura, Forma, Espaço e Ordem. São Paulo: Martins Fontes, 1998. 


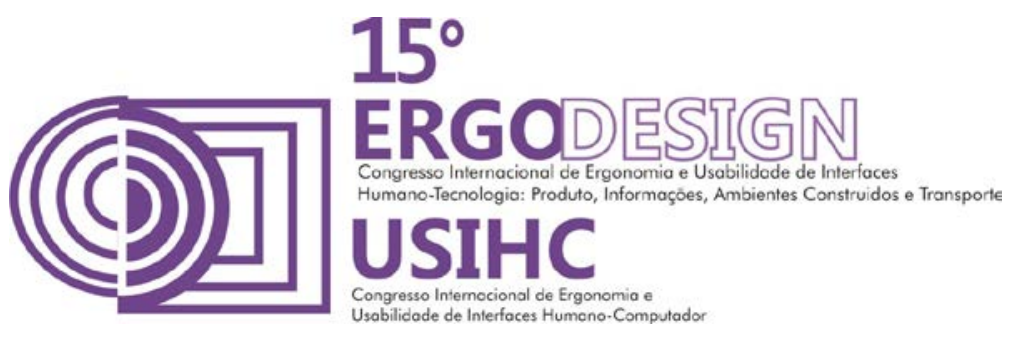

COUTINHO, E. O Espaço da Arquitetura. São Paulo: Perspectiva, 1977.

DE CARVALHO, G. L. Ambientes Cognitivos para Projetação: um estudo relacional entre as mídias tradicional e digital na concepção do projeto arquitetônico. 260f. Tese (doutorado) - Universidade Federal de Pernambuco. CAC. Desenvolvimento Urbano, 2004.

DE SOUZA, Flávio et al. Limites e potencialidades do instituto das ZEIS em Recife na resolução de conflitos por demandas habitacionais: uma revisão crítica. XXVIII Congresso Internacional ALAS. UFPE, Recife-PE, 2011.

DEL RIO, Vicente. Arquitetura: Pesquisa \& Projeto. Ed. PROARQ/FAU/UFRJ e Proeditores, 1998.

DORNELES, Vanessa et al. Ensino de desenho universal em cursos de arquitetura e urbanismo no Brasil. In: Cláudia Mont'Alvão e Vilma Villarouco (Orgs.). Um novo olhar para o projeto: a ergonomia no ambiente construído - Recife: Editora UFPE, 2014. 247p.

DOS SANTOS,Caroline. De cima para baixo e de baixo para cima: intervenção estatal e investimentos habitacionais em assentamentos de baixa renda do Recife. Recife: O autor, 2011.

INSTITUTO FEDERAL DA BAHIA (IFBA). Plano de Curso de Edificações modalidade Integrada do IFBA Feira de Santana, 2011.

JACQUES, Paola Berenstein. Estética da ginga: A arquitetura das favelas através da obra de Hélio Oiticica. Rio de Janeiro: Casa da Palavra, 2003.

KOWALTOWSKI, Doris et al. Arquitetura escolar e seu processo de projeto. In: Doris C.C.K.Kowaltowski, Daniel de Carvalho Moreira, João R.D.Petreche, Mário M. Fabricio (Orgs.). O processo do projeto em arquitetura. São Paulo: Oficina de textos, 2011.

LEITE, Luiz Carlos. Avaliação de projetos habitacionais: determinando a funcionalidade da moradia social. São Paulo: Ensino Profissional, 2006. 161p.

NOBERG SCHULZ, Christian. El significado de la Arquitectura Occidental. Colección Summa. La arquitectura Paleocristiana. Buenos Aires, 1973.

OLIVEIRA, Gilberto; MONT'ALVÃO, Cláudia. Método e metodologia projetual: o que dizem os profissionais de design de interiores e arquitetos sobre o processo?. In: Cláudia Mont'Alvão e Vilma Villarouco (Orgs.). Um novo olhar para o projeto: a ergonomia no ambiente construído - Recife: Editora UFPE, 2014. 247p.

RAPOSO, Maria Monica. Casa mínima e projeto em Santana-Parnamirim. Recife : Editora UFPE, 2012.117p.

SÃO PAULO (PREFEITURA). Secretaria da Habitação e Desenvolvimento Urbano. Comissão Permanente de Acessibilidade. Manual de Desenho Universal: habitação de interesse social. São Paulo, nd.

SILVA. Elvan. Uma introdução ao projeto arquitetônico. Porto Alegre: Editora da UFRGS, 1991.

VOORDT, T. JM van der; WEGEN, H. BR van. Architecture in Use: An Introduction to the Programming, Design and Evaluation of Buildings. United Kingdon: Elsevier, 2005.

ZEVI, Bruno. Saber Ver a Arquitetura. São Paulo, Ed. Martins Fontes, 1996. 